\section{OPEN ACCESS}

Edited by:

Luigi Boccuto,

Clemson University, United States

Reviewed by:

Enzo Lalli,

UMR7275 Institut de Pharmacologie

Moléculaire et Cellulaire (IPMC), France

Emilia Modolo Pinto,

St. Jude Children's Research

Hospital, United States

${ }^{*}$ Correspondence:

Evelina Miele

evelina.miele@opbg.net

Specialty section: This article was submitted to

Pediatric Oncology,

a section of the journal

Frontiers in Oncology

Received: 21 April 2020 Accepted: 20 August 2020

Published: 15 October 2020

Citation:

Miele E, Di Giannatale A, Crocoli A, Cozza R, Serra A, Castellano A, Cacchione A, Cefalo MG, Alaggio $R$ and De Pasquale MD (2020) Clinical, Genetic, and Prognostic Features of Adrenocortical Tumors in Children: A 10-Year Single-Center Experience.

Front. Oncol. 10:554388.

doi: 10.3389/fonc.2020.554388

\title{
Clinical, Genetic, and Prognostic Features of Adrenocortical Tumors in Children: A 10-Year Single-Center Experience
}

\section{Evelina Miele ${ }^{1 *}$, Angela Di Giannatale ${ }^{1}$, Alessandro Crocoli ${ }^{2}$, Raffaele Cozza ${ }^{1}$, Annalisa Serra ${ }^{1}$, Aurora Castellano ${ }^{1}$, Antonella Cacchione ${ }^{1}$, Maria Giuseppina Cefalo ${ }^{1}$, Rita Alaggio $^{3}$ and Maria Debora De Pasquale ${ }^{1}$}

1 Department of Paediatric Haematology/Oncology Cell and Gene Therapy, Bambino Gesù Children's Hospital, IRCCS, Rome, Italy, ${ }^{2}$ Department of Surgery, Bambino Gesù Children's Hospital, IRCCS, Rome, Italy, ${ }^{3}$ Department of Laboratories, Pathology Unit, Bambino Gesù Children's Hospital, IRCCS, Rome, Italy

Background and Aims: Pediatric adrenocortical tumors (ACTs) are very rare endocrine neoplasms in childhood. In this study, we performed a retrospective analysis of children with ACT treated at our institution by examining clinical and genetic disease features, treatment strategies, and outcomes.

Methods: We retrospectively analyzed a cohort of 13 children treated at the Bambino Gesù Children's Hospital from November 2010 to March 2020.

Results: The median age at diagnosis was 17 months (range $=0-82$ months). The female: male ratio was 3.3/1. Mixed symptomatology ( $>1$ hormone abnormality) was the most common presentation (46.1\%). In three cases, the tumor was detected during prenatal or perinatal echographic screening. All patients presented with localized disease at diagnosis and underwent total adrenalectomy. Six patients were identified as having malignancies according to the Wieneke scoring system, five benign, and two undetermined. Seven patients underwent mitotane adjuvant therapy for 12 months. There was metastatic disease in three patients, with no correlation with age or Wieneke score. The most common sites of metastases were the liver and lungs. Metastatic patients were treated with surgery $(n=2)$, mitotane $(n=$ $1)$, chemotherapy $(n=2)$ associated with anti-EGFR $(n=1)$, or immunotherapy with anti-PD1 (pembrolizumab) $(n=1)$; two patients achieved complete disease remission. Overall 2- and 5-year survival rates were 100\%, with a median follow-up of 5 years (range $=2-9.5$ years). Two- and 5-year disease free survival was 76.9 and $84.6 \%$, respectively (95\% confidence interval $=-66.78-114.76$ months). All patients are alive, 12 without disease, and one with stable disease. Genetic analyses showed TP53 germline mutations in six of eight patients analyzed (five inherited, one de novo). One patient had Beckwith-Wiedemann syndrome, with mosaic paternal uniparental disomy of chromosome 11, in both neoplastic and healthy adrenal tissue. 
Conclusion: We report the cases of 13 patients treated for ACT, including 12 aged $<4$ years at diagnosis, with a relative short time from symptoms onset. Our cohort experienced an excellent prognosis. TP53 mutation was found in 75\% of tested patients (6/8) confirming the need to perform genetic tests and familial counseling in this disease.

Keywords: adrenocortical tumors, children, Li-Fraumeni Syndrome, Beckwith-Wiedeman syndrome, mitotane, immunotherapy, targeted therapies, prognosis

\section{INTRODUCTION}

Pediatric adrenocortical tumors (ACTs) include both benign adrenocortical adenomas (ACA) and highly aggressive adrenocortical carcinomas (ACC). They are very rare neoplasms of childhood, with a reported incidence of just $0.2-0.3$ new cases per 1 million children per year $(1,2)$ and accounting for $6 \%$ of all adrenal cancers in children (3). ACC incidence rises of 10-15 times the worldwide rate in Southern Brazil, which is likely associated with high prevalence of the founder p.R337H TP53 mutation (4). ACT can occur in the context of several cancer predisposition syndromes; in fact, most childhood ACC are linked to genetic susceptibility, although their pathogenesis is not completely understood (5). Prognosis of pediatric ACT patients is highly heterogeneous and hardly predictable in clinical practice. There is considerable variability in clinical presentation, from tumors with an indolent clinical course to highly malignant tumors with dismal prognosis. Risk factors for poor outcomes in patients with ACT include older age, higher mitotic rate, higher percent of necrosis, and larger tumor size (3). In some cases, a delayed diagnosis may contribute to advanced stages and poor prognosis in these patients (3).

Pediatric ACC patients generally have overall 5-year survival ranging from 30 to $70 \%$, depending on disease presentation (6-8). Despite multimodal therapeutic approaches, outcomes remain poor in patients with metastatic disease, with an estimated 5-year survival $<20 \%(1,2,7,9-11)$. No effective therapy is currently available for advanced and metastatic ACC; the only treatment leading to cure and long-term survival remains complete surgical resection $(6,7)$. Adjuvant mitotane, chemotherapy, and/or radiotherapy may reduce recurrence. Arterial chemoembolization, radiotherapy, and radiofrequency ablation are treatment options reported in cases of advanced disease in adulthood $(2,12,13)$. However, because many children with ACT carry germline TP53 mutations, radiation therapy in pediatric ACTs has not been studied and should be avoided $(6,14)$. On the other hand, ACA histology is associated with excellent prognosis, but only about $20 \%$ of pediatric ACTs are identified as ACA, and the correct distinction between adenoma and carcinoma is difficult (15). Indeed, there are no well-defined pathological malignancy criteria for pediatric ACT, whereas adult tumors can be classified based on Weiss or Van Slooten criteria $(16,17)$. The Wieneke criteria, considering tumor size, local invasion, and histological features, are reported useful in discriminating benign from malignant tumors and predicting the prognosis of pediatric $\operatorname{ACT}(11,18)$.
In the present study, we performed a retrospective analysis examining clinical and genetic disease features, treatment strategies, and outcomes in children with ACT in a single institution.

\section{METHODS}

We retrospectively reviewed medical records of children affected by ACT and admitted to our hospital between November 2010 and March 2020. All patients included in this study were $<18$ years old with ACT confirmed by pathological review. The following data were collected: general clinical features (gender, age, clinical symptoms, and signs), imaging, pathological characteristics, and prognosis.

Given our interest in examining genetic factors in this disease, TP53 mutations analysis was performed on peripheral blood DNA samples from the patients and their parents, by using BigDye direct Sanger sequencing of exons 2-11 and intron-exon boundaries of polymerase chain reaction products by an ABI automated sequencer (Applied Biosystems, Foster City, CA). Gene dosage was evaluated by multiplex ligation-dependent probe amplification (MLPA) using the MRCHolland SALSA MLPA PO56 TP53 probe set (MRC-Holland, Amsterdam, the Netherlands) according to the manufacturer's instructions. Chromosome microarray analysis was performed in patients 1 (blood sample) and 9 (blood, saliva, skin fibroblasts, healthy and neoplastic adrenal samples) by using SNP- array (single-nucleotide polymorphism array) on platform CytoSNP$850 \mathrm{~K}$ BeadChip (Illumina, San Diego, CA) with an average resolution of $100 \mathrm{~Kb}$. Outcomes were reported as alive with no evidence of disease, alive with evidence of disease, and dead of disease. The Wieneke index was applied for diagnosis and prognosis definition.

\section{RESULTS}

This retrospective cohort included 13 children. Median age at pathological diagnosis was 17 months (range $=0-82$ months). Female-to-male ratio was $3.3 / 1$ (Table 1). Mixed symptomatology ( $>1$ hormone abnormality) was the most common presentation $(46.1 \%, n=6$ ), (Table 1$)$. In three cases (patients 5, 7, and 13), diagnosis was performed in asymptomatic patients via prenatal (patient 13) or perinatal echographic screening for congenital dysplasia of the hip (patients 5 and 7). All patients presented with localized disease at diagnosis and underwent total adrenalectomy by laparotomy $(n=12)$ or 
laparoscopic surgery ( $n=1$, patient 13 ; Table 2 ). The Wieneke score system was applied for diagnosis and prognosis definition: six patients were assigned to the malignant category, five to the benign category, and two had a diagnosis of tumor with uncertain biological behavior (indeterminate), (Table 3).

Seven patients underwent mitotane-based adjuvant therapy for 12 months (Table 2). Metastatic disease appeared in three patients after 3, 18, and 42, months, respectively, in one case under treatment and in two during follow-up. No correlation with age or with Wieneke category was observed in metastatic/relapsed patients (the Fisher exact test was not significant). The most common sites of metastases were the liver and lungs. Relapsed and metastatic patients were treated with surgery ( 2 patients), mitotane (1 patient), chemotherapy

TABLE 1 | Clinical features at presentation of 13 pediatric patients with adrenocortical tumors.

\begin{tabular}{|c|c|c|c|}
\hline Clinical feature & $\begin{array}{l}\text { All patients }(n= \\
\text { 13) }\end{array}$ & $\begin{array}{c}\text { Age }<24 \text { months } \\
(n=8)\end{array}$ & $\begin{array}{c}\text { Age } \geq 24 \text { months } \\
(n=5)\end{array}$ \\
\hline \multicolumn{4}{|c|}{ Age at onset of symptoms, months } \\
\hline Median & 17 & 5.5 & 39 \\
\hline Range & $0-82$ & $0-22$ & $24-82$ \\
\hline \multicolumn{4}{|l|}{ Sex, $n$} \\
\hline Male & 3 & 2 & 1 \\
\hline Female & 10 & 6 & 4 \\
\hline Female:male ratio & 3.3:1 & $3: 1$ & $4: 1$ \\
\hline \multicolumn{4}{|l|}{ Type of presentation, $n$} \\
\hline Virilization only ${ }^{\mathrm{a}}$ & $3(23.1 \%)$ & 2 & 1 \\
\hline Cushing syndrome only & 0 & 0 & 0 \\
\hline Hypertension only & 0 & 0 & 0 \\
\hline Mixed tumor & $6(46.1 \%)$ & 3 & 3 \\
\hline Asymptomatic & $3(23.1 \%)$ & 3 & 0 \\
\hline Unknown ${ }^{\mathrm{b}}$ & $1(7.7 \%)$ & 0 & 1 \\
\hline \multicolumn{4}{|c|}{ Duration of symptoms, months } \\
\hline Median & 1 & 0.5 & 1 \\
\hline Range & $0-10$ & $0-10$ & $1-3$ \\
\hline
\end{tabular}

a Indicated by clinical and/or laboratory evidence of abnormal production of more than one hormone, ${ }^{b}$ The patient was diagnosed at another institution, and the initial medical records were not available.
(2 patients) associated or not with anti-EGFR (1 patient), or immunotherapy with anti-PD1 (pembrolizumab) (1 patient); two patients achieved complete disease remission (Figure 1). Overall 2- and 5-year survival rates were both $100 \%$, with a median follow-up of 5 years (range $=2-9.5$ years). Two- and 5 year disease-free survival was 76.9 and $84.6 \%$, respectively (95\% confidence interval $=-66.78-114.76$ months). At present, 12 patients are alive with no evidence of disease, and one is alive with evidence of metastatic disease.

Genetic analyses were conducted for eight patients showing TP53 germline mutations in six (five inherited and one de novo) (Table 4). The most part of detected mutations were already recognized as pathogenic. All the carrier parents were asymptomatic, but family history was positive for cancer in four patients (Table 4). In two cases, it was strongly suggestive of LiFraumeni syndrome (LFS) for the tumor histotypes (e.g., alveolar rhabdomyosarcomas, choroid plexus carcinoma) and the very young age of the affected individuals (Figure 2). One patient (patient 9) had Beckwith-Wiedemann syndrome (BWS) with clinical features (macrosomia, hyperinsulinism, hyperglycemia, and tumor) and paternal uniparental disomy of chromosome 11 on neoplastic and healthy adrenal tissue. Another patient (patient 1) showed a copy number variation of uncertain significance, involving a region $1.7 \mathrm{Mb}$ on $8 \mathrm{q} 21.3 \mathrm{q} 22.1$, not involving OMIM genes.

\section{DISCUSSION}

Pediatric ACTs are very rare endocrine tumors in childhood with a highly heterogeneous and challenging prognosis. Recognized independent prognostic factors are older age $(3,10)$ and metastasis at the time of diagnosis (3), which in some cases could be attributed to delayed diagnosis. Our cohort is characterized by an excellent prognosis on long-term follow-up (media $n=5$ years). Indeed, at present 12 patients are alive with no evidence of disease, and one is alive with evidence of metastatic disease. The $93 \%$ of patients were aged $<4$ years at diagnosis and with relative short time from symptoms onset (Table 1). Three patients were diagnosed in the course of other care, one prenatally and the other two through echographic evaluation for neonatal screening or urinary tract infection.

TABLE 2 | Therapeutic approach.

\begin{tabular}{|c|c|c|c|c|}
\hline $\begin{array}{l}\text { Surgery/no. of } \\
\text { patients }\end{array}$ & $\begin{array}{l}\text { Adjuvant mitotane/no. of } \\
\text { patients }\end{array}$ & $\begin{array}{l}\text { Chemotherapy/no. } \\
\text { of patients }\end{array}$ & $\begin{array}{l}\text { Immunotherapy/no. } \\
\text { of patients }\end{array}$ & $\begin{array}{l}\text { Outcome/no. of } \\
\text { patients }\end{array}$ \\
\hline LTUA/8 & No/6 & $\mathrm{No} / 11$ & $\mathrm{No} / 11$ & $\mathrm{CR} / 12$ \\
\hline $\begin{array}{l}\text { LTUA + } \\
\text { linfoadenectomy/3 }\end{array}$ & Yes/7 & Yes $/ 2^{\star \wedge}$ & Yes $/ 2^{\circ}$ & $\mathrm{SD} / 1^{\bullet}$ \\
\hline \multicolumn{5}{|l|}{$\begin{array}{l}\text { LTUA + bioptic } \\
\text { sampling } / 1\end{array}$} \\
\hline LUA/1 & & & & \\
\hline
\end{tabular}

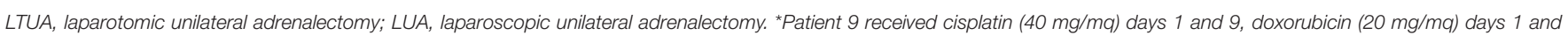

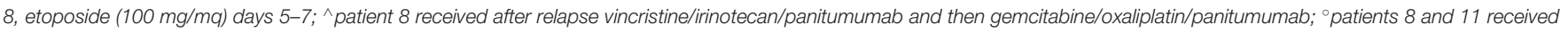
pembrolizumab; 'patient 8. 
TABLE 3 | Pathological features in childhood ACT.

\begin{tabular}{|c|c|c|c|c|c|c|c|c|c|c|c|c|}
\hline$\#$ & $\begin{array}{l}\text { Tumor } \\
\text { size }\end{array}$ & $\begin{array}{l}\text { Growth } \\
\text { pattern }\end{array}$ & $\begin{array}{l}\text { Ki67 } \\
(\%)\end{array}$ & $\begin{array}{l}\text { Atypical } \\
\text { mitosis }\end{array}$ & $\begin{array}{l}\text { Nuclear } \\
\text { pleomorphism }\end{array}$ & Necrosis & $\begin{array}{l}\text { Capsular } \\
\text { invasion }\end{array}$ & $\begin{array}{l}\text { Vascular } \\
\text { invasion }\end{array}$ & $\mathbf{N}+$ & $\mathbf{M}+$ & Other & $\begin{array}{l}\text { Wieneke } \\
\text { score }\end{array}$ \\
\hline 1 & $77 \mathrm{~g}$ & Diffuse & $2-8$ & No & No & Yes & No & Yes & No & No & $\begin{array}{l}\text { Reticolinic } \\
\text { pattern } \\
\text { anomalies }\end{array}$ & Benign \\
\hline & $6 \times 5.5 \times 4 \mathrm{~cm}$ & & & & - & & & & & & & \\
\hline 2 & $20 \mathrm{~g}$ & Diffuse & 5 & Yes & Yes & No & Yes & No & No & No & $\begin{array}{l}\text { p53 + + + } \\
\text { nuclear }\end{array}$ & Intermediate \\
\hline & $2.5 \times 2 \times 1 \mathrm{~cm}$ & & & & ++ & & & & & & & \\
\hline 3 & $\begin{array}{c}100 \mathrm{~g} \\
8 \times 6.5 \times 5 \mathrm{~cm}\end{array}$ & Diffuse & 30 & Yes & $\begin{array}{l}\text { Yes } \\
+++\end{array}$ & Yes & No & Yes & No & No & p53 + 70\% & Malignant \\
\hline 4 & $\begin{array}{c}159 \mathrm{~g} \\
9 \times 7 \times 4.5 \mathrm{~cm}\end{array}$ & Solid & $10-40$ & Yes & $\begin{array}{l}\text { Yes } \\
+++\end{array}$ & Yes & Yes & Yes & No & No & / & Malignant \\
\hline 5 & $\begin{array}{c}40 \mathrm{~g} \\
3.2 \times 2.5 \times 2 \mathrm{~cm}\end{array}$ & Solid & $5-10$ & No & $+/-$ & No & No & Yes & No & No & p53 neg & Benign \\
\hline 6 & $50 \mathrm{~g}$ & Solid & 2 & No & Yes & No & No & No & No & No & $\begin{array}{l}\text { p53+ } \\
\text { nuclear } \\
10 \%\end{array}$ & Benign \\
\hline & $2.5 \times 2 \times 3.5 \mathrm{~cm}$ & & & & + & & & & & & & \\
\hline 7 & $\begin{array}{c}10 \mathrm{~g} \\
3.5 \times 3 \times 1.5 \mathrm{~cm}\end{array}$ & Diffuse & 20-30 & Yes & $\begin{array}{l}\text { Yes } \\
+++\end{array}$ & Yes & Yes & No & No & No & p53 + & Intermediate \\
\hline 8 & $\begin{array}{c}49.3 \mathrm{~g} \\
5.5 \times 4.5 \times 4 \mathrm{~cm}\end{array}$ & Solid & $30-40$ & Yes & $\begin{array}{l}\text { Yes } \\
+++\end{array}$ & Yes & No & Yes & No & No & p53 + & Malignant \\
\hline 9 & $\begin{array}{c}50 \mathrm{~g} \\
6 \times 5 \times 4 \mathrm{~cm}\end{array}$ & Diffuse & $20-30$ & Yes & $\begin{array}{l}\text { Yes } \\
+++\end{array}$ & Yes & Yes & Yes & Yes & No & p53 + & Malignant \\
\hline 10 & $\begin{array}{c}33 \mathrm{~g} \\
5 \times 4 \times 2.5 \mathrm{~cm}\end{array}$ & Solid & 8 & No & No & Yes, focal & No & No & No & No & p53 neg & Benign \\
\hline $11^{*}$ & NA & Solid & High & Yes & $\begin{array}{l}\text { Yes } \\
+++\end{array}$ & Yes & na & No & na & No & / & Malignant \\
\hline 12 & $\begin{array}{c}48 \mathrm{~g} \\
5.5 \times 4.5 \times 4 \mathrm{~cm}\end{array}$ & Solid & $15-20$ & Yes & $\begin{array}{l}\text { Yes } \\
+++\end{array}$ & Yes & Yes & Yes & No & No & p53 -/+ & Malignant \\
\hline 13 & $\begin{array}{c}18 \mathrm{~g} \\
5 \times 3.7 \times 2.5 \mathrm{~cm}\end{array}$ & Diffuse & $5-30$ & No & No & No & No & No & No & No & p53 +/- & Benign \\
\hline
\end{tabular}

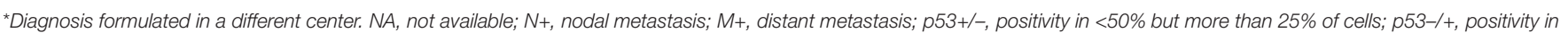
$<25 \%$ of cells.

Routine prenatal ultrasound examinations have increased the detection of fetal tumors; some specific imaging features together with magnetic resonance imaging may help in the differential diagnosis as other common fetal abnormalities can sometimes mimic fetal tumors (26). This is very important for appropriate prenatal management of pregnancy and delivery in order to facilitate prompt postnatal treatment (26). Similarly, ultrasound screening in pediatric population can be used to reveal lesions like tumors or other pathologies of developmental age that are undetectable by clinical examination, before the onset of clinical symptoms $(27,28)$. This is particularly appropriate for patients with cancer predisposition, for example, in children with BWS $(27,29)$.

Although adult ACCs are classified following Weiss score, Ki67 $>10 \%$ and European Network for the Study of Adrenal Tumors for tumor stage (17), there are no clear pathological malignancy criteria for pediatric patients. Higher mitotic rate, higher percent of necrosis, and larger tumor size are usually associated with aggressive behavior (3). The Wieneke criteria, which include tumor size, local invasion, and histological features, have been reported useful in pediatric ACT malignancy definition and prognosis prediction (11, 18, 30). Recently, Picard and colleagues (31) proposed a pathological scoring system incorporating the Ki67 index $\geq 15 \%$ in a prognostication algorithm to guide adjuvant treatment in pediatric ACTs, mostly for those with incomplete resection. In our cohort, the Wieneke score could not predict clinical outcomes in patients who experienced metastatic disease.

Treatment of pediatric ACTs is often based on the results of adult studies, and the same guidelines are applied (6). When achievable, radical surgery remains the only successful treatment strategy. Capsule rupture with consequent tumor spreading, however, can be a frequent complication due to the tumor friability, mostly during laparoscopic resection. Thus, adrenalectomy in laparotomy is considered the standard of care $(6,32)$. We were able to perform surgery in all of our patients; 

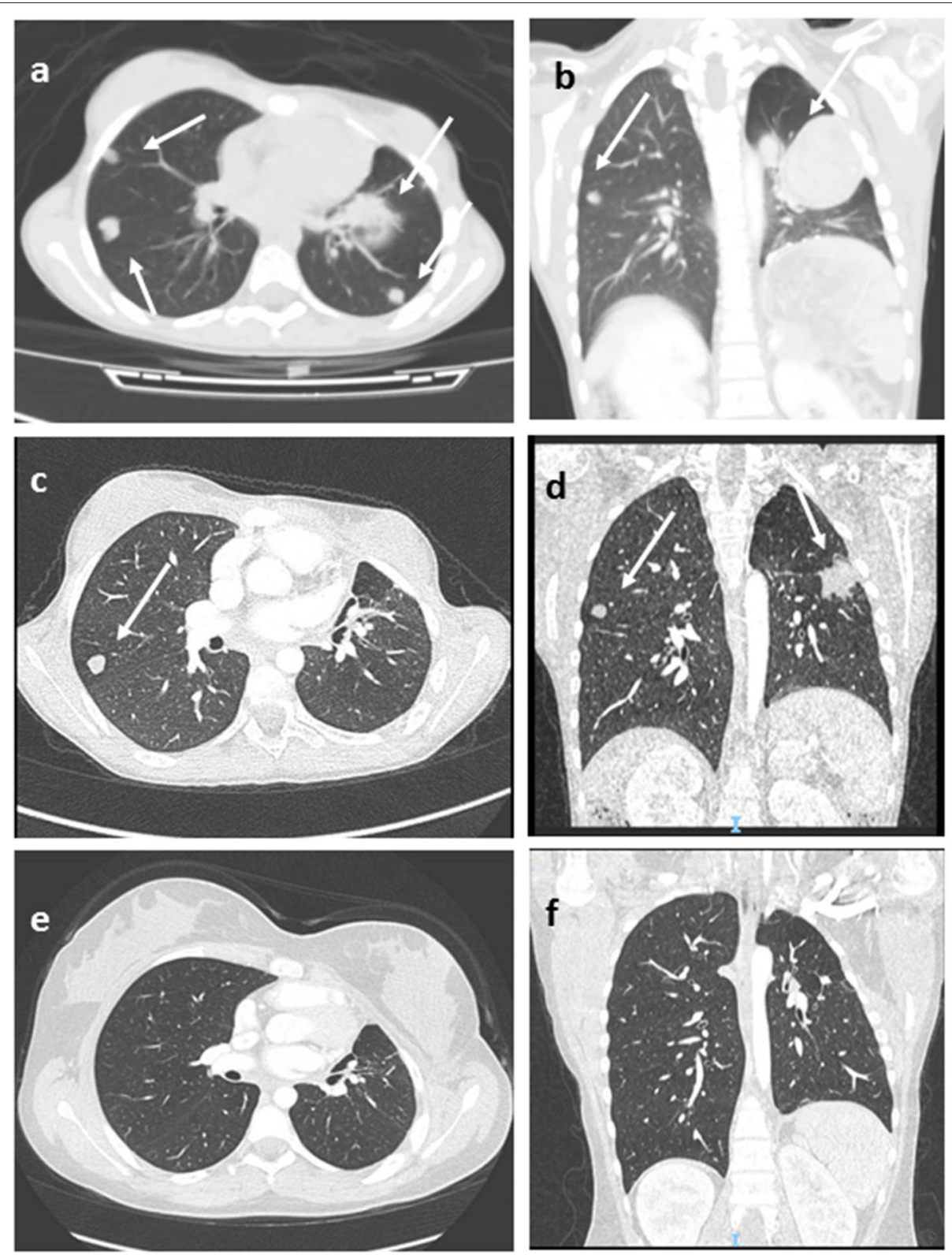

FIGURE 1 | Lung Computed tomography (CT) images (patient \#11) showing multiple metastatic lesions (arrows), before (a,b), after 3 months of pembrolizumab

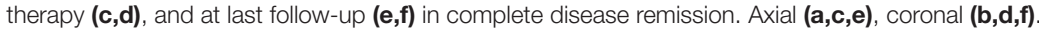

open laparotomy was the preferred choice. Laparoscopy was used in one case by the neonatal surgeon for the antenatal diagnosed lesion, given the suspicion of a benign adrenal tumor. Careful follow-up with clinical, radiographic, and endocrine evaluation is mandatory after surgery to detect recurrence and metastasis early.

Adjuvant therapies for ACC have not been successful (6). Both radiation and chemotherapy are poorly effective, and the role of mitotane is not completely clear. Mitotane is a derivative of the insecticide dichlorodiphenyltricholorethane and has been used for treating ACC for more than five decades, also in association with chemotherapy $(18,33)$. It is the only drug approved for
ACC by the US Food and Drug Administration, characterized by low efficacy rate and a narrow therapeutic window, which often involves serious toxicity $(34,35)$. Current evidence highlighted by a comprehensive review indicates that adjuvant mitotane significantly reduced the recurrence rate and mortality after surgery in nonmetastatic ACC patients $(13,18,32)$. In our cohort, mitotane-based adjuvant therapy was administered for 12 months in seven patients with an acceptable tolerability and quality of life.

Despite the known ACC radioresistance, adjuvant radiotherapy of the tumor bed has been proposed and recommended in adult patients with microscopically incomplete 
TABLE 4 | Genetic finding: TP53 mutations features in tested patients.

\begin{tabular}{|c|c|c|c|c|c|c|c|c|}
\hline \# & Exon & Codon & $\begin{array}{l}\text { Nucleotide } \\
\text { mutation }\end{array}$ & $\begin{array}{l}\text { Type of } \\
\text { mutation }\end{array}$ & $\begin{array}{l}\text { Amino acid } \\
\text { change }\end{array}$ & Germline/Somatic & $\begin{array}{l}\text { LFS association } \\
\text { (according to } \\
\text { ClinVar) }\end{array}$ & Family history \\
\hline \#3 & 5 & 538 & $\mathrm{G}>\mathrm{A}$ & $\begin{array}{l}\text { Missense } \\
\text { Heterozygosis }\end{array}$ & pGlu180Lys & $\begin{array}{l}\text { Germline (maternal } \\
\text { segregation) }\end{array}$ & $\begin{array}{l}\text { Likely pathogenic } \\
\text { (20) }\end{array}$ & $\begin{array}{l}\text { Breast cancer in } \\
\text { maternal grandmother }\end{array}$ \\
\hline \#7 & 5 & 455 & $C>T$ & $\begin{array}{l}\text { Missense } \\
\text { Heterozygosis }\end{array}$ & pPro152Leu & $\begin{array}{l}\text { Germline (maternal } \\
\text { segregation) }\end{array}$ & Pathogenic (23) & $\begin{array}{l}\text { Brain tumor (NOS) in } \\
\text { maternal grandfather } \\
\text { (50 years-old) }\end{array}$ \\
\hline \#8 & 7 & 742 & $\mathrm{C}>\mathrm{T}$ & $\begin{array}{l}\text { Missense } \\
\text { Heterozygosis }\end{array}$ & p.Arg248Trp & $\begin{array}{l}\text { Germline (paternal } \\
\text { segregation) }\end{array}$ & $\begin{array}{l}\text { Pathogenic } \\
(23,24)\end{array}$ & $\begin{array}{l}\text { Alveolar } \\
\text { rhabdomyosarcoma in } \\
\text { her brother ( } 2 \text { years old) }\end{array}$ \\
\hline
\end{tabular}

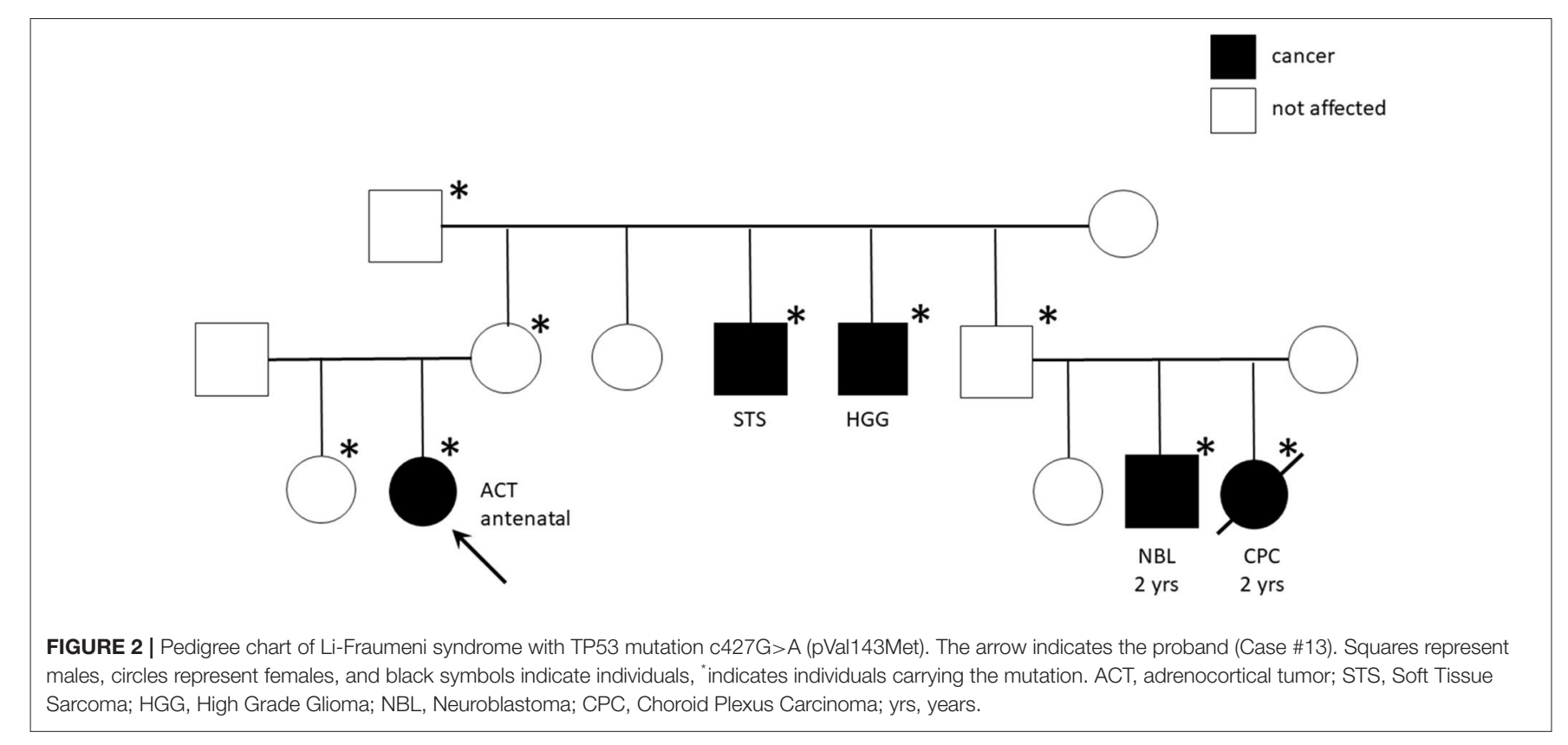

resection $(17,18,36)$. In pediatric population, radiation therapy has not been investigated for the high probability for patients of carrying germline TP53 mutations and thus should be avoided.

No effective therapy is currently available for advanced and metastatic ACC; the only treatment allowing cure and long-term survival remains complete surgical resection $(12,37)$. Systemic chemotherapy and mitotane therapy are considered valuable therapeutic options in the treatment of advanced pediatric ACC patients $(6,38-40)$. Duration of mitotane treatment longer than 6 months and mitotane levels $>14 \mathrm{mg} / \mathrm{L}$ were found to be associated with significantly better survival (38). The
FIRM-ACT trial was conducted to determine whether treatment with etoposide, doxorubicin, cisplatin, and mitotane (EDP/M) prolonged survival as compared to streptozotocin and mitotane $(\mathrm{Sz} / \mathrm{M})$ in patients with inoperable advanced ACC. Rates of response and progression-free survival were significantly better with EDP plus mitotane as first-line therapy, with similar rates of toxic events [58\%), but no significant differences in OS were observed (12)]. In our experience, one of the three patients who experienced metastatic disease obtained complete remission with platinum-based chemotherapy and mitotane. Overexpression of the IGF2 and IGF1R genes was described in ACT also in the 
pediatric setting (41), but trials testing the utility of insulin like growth factor receptor 1 inhibitors (e.g., linsitinib) have failed to provide advantage for adulthood ACC treatment (42).

Immunotherapy approaches have been recently investigated for this disease. In advanced ACC, pembrolizumab showed a significant and durable antitumor activity with a manageable safety profile (43-45). In the recent interim analysis of the phases 1-2 study, KEYNOTE-051 conducted in the pediatric setting, two of four patients with ACC showed partial responses to pembrolizumab therapy (46). In our cohort, two patients were treated by immunotherapy. Patient 8 showed early progressive disease. Patient 11 obtained durable complete remission after 24 months of pembrolizumab therapy (Figure 1). She is alive in not-evident disease after 3 years of follow-up.

Most childhood ACCs are reported in the context of cancer predisposition syndromes, in particular the Carney complex (CNC), the BWS, and the LFS. CNC, mostly due to germline inactivating mutations of PRKAR1A, is rarely associated with ACC but is the main cause of primary pigmented nodular adrenal diseases and usually linked to other tumors (somatotroph pituitary adenomas, thyroid, breast, and bone tumors, Sertoli tumors, melanocytic schwannoma, and cardiac and cutaneous myxomas) (5).

BWS is an overgrowth and tumor predisposition syndrome caused by genetic or epigenetic changes at the 11 p15 locus. Childhood ACCs, together with embryonal tumors, represent the standard tumor spectrum of BWS (5). In our case studies, one patient was first clinically diagnosed with BWS, due to macrosomia, hyperinsulinism, hypoglycemia, and tumor at 1 month old. Then, the diagnosis of mosaic BWS was genetically confirmed by the evidence of chromosome 11 trisomy on healthy and neoplastic adrenal tissue but not on peripheral lymphocytes. Notably, this patient developed metastatic disease 3 months after surgery, treated by chemotherapy and mitotane, obtaining a complete remission with a 7-year follow-up.

LFS is a dramatic cancer predisposition syndrome, caused by germline inactivating mutations of TP53 that highly expose to various and precocious cancer risk. Among the most common tumors in LFS are premenopausal breast cancer, soft-tissue sarcoma, osteosarcoma, central nervous system tumors, and ACC, the latter accounting for the $50-80 \%$ of pediatric cases. We found TP53 mutation in 75\% of tested patients (6/8) underlining the need to predict carrier and familial disease penetrance with potentially broad implications for clinical surveillance and counseling. Of note, the familial history was positive for cancer in four patients with TP53 mutation and highly suggestive of LFS in two cases for the tumor histotypes and the very young age of the affected individuals. The most part of detected mutations were indeed already recognized as pathogenic (Table 3). In particular, the R248W missense TP53 mutant that we found in patient 8 has been described to gain novel oncogenic activities $(23,26,47)$. Interestingly, Pinto et al. (48) have investigated the clinicopathologic characteristics and outcomes of children with ACT without germline TP53 mutations. They found overlapping features with those reported for children with germline TP53 mutations, highlighting the central role of genetic or epigenetic alterations on chromosome $11 \mathrm{p} 15$ in pediatric ACT (48).

\section{CONCLUSION}

Our experience with an ACT patient cohort of very young patients (12/13 aged $<4$ years at diagnosis), with relative short time from symptoms onset and localized disease at diagnosis, suggests an excellent prognosis with appropriate and aggressive diagnosis, staging, and surgical treatment. Our experience confirms age and metastasis as independent prognostic factors and the importance of early diagnosis, supported by already recommended echographic screening in neonates. In our patients, use of the Wieneke index, which is reported to be most accurate in predicting clinical outcomes in younger children, could not predict clinical outcomes.

We were able to treat all patients with surgery. Adjuvant mitotane was offered to 7 of 13 patients for 12 months with acceptable tolerance and no disease recurrence during therapy. In patients who developed metastatic disease, both immunotherapy and chemotherapy led to disease remission or control.

TP53 mutation was found in 75\% of tested patients confirming the need to perform genetic tests and familial counseling in this disease.

\section{DATA AVAILABILITY STATEMENT}

The raw data supporting the conclusions of this article will be made available by the authors, without undue reservation.

\section{INFORMED CONSENT}

The authors declare that written informed consent was obtained from the patients' parents.

\section{ETHICS STATEMENT}

The studies involving human participants were reviewed and approved by Bambino Gesù Children's Hospital Ethical Committee. Written informed consent to participate in this study was provided by the participants' legal guardian/next of kin. Written informed consent was obtained from the minor(s)' legal guardian/next of kin for the publication of any potentially identifiable images or data included in this article.

\section{AUTHOR CONTRIBUTIONS}

EM: conception (ideation), design of the work, structuration, acquisition of the data, writing, revision, and final approval to be published. ADG: structuration and interpretation of the data ACro: surgery acquisition of 
the data and revision. $\mathrm{RC}, \mathrm{AS}, \mathrm{ACac}, \mathrm{ACas}$, and $\mathrm{MC}$ : patients' management and revision. MDP: patients' management, structuration, and interpretation of the data. All authors contributed to the article and approved the submitted version.

\section{REFERENCES}

1. Gupta N, Rivera M, Novotny P, Rodriguez V, Bancos I, Lteif A. Adrenocortical carcinoma in children: a clinicopathological analysis of 41 patients at the Mayo Clinic from 1950 to 2017. Horm Res Paediatr. (2018) 90:818. doi: $10.1159 / 000488855$

2. Else T, Kim AC, Sabolch A, Raymond VM, Kandathil A, Caoili EM, et al. Adrenocortical carcinoma. Endocr Rev. (2014) 35:282-326. doi: 10.1210/er.2013-1029

3. Klein JD, Turner CG, Gray FL, Yu DC, Kozakewich HP, Perez-Atayde AR, et al. Adrenal cortical tumors in children: factors associated with poor outcome. J Pediatr Surg. (2011) 46:1201-7. doi: 10.1016/j.jpedsurg.2011.03.052

4. Lalli E, Figueiredo BC. Pediatric adrenocortical tumors: what they can tell us on adrenal development and comparison with adult adrenal tumors. Front Endocrinol. (2015) 6:23. doi: 10.3389/fendo.2015.00023 (cited July 30, 2020).

5. Jouinot A, Bertherat J. Diseases predisposing to adrenocortical malignancy (Li-Fraumeni syndrome, Beckwith-Wiedemann syndrome, and carney complex) Exp Suppl. (2019) 111:149-69. doi: 10.1007/978-3-030-25905-1_9

6. Pinto EM, Zambetti GP, Rodriguez-Galindo C. Pediatric adrenocortical tumours. Best Pract Res Clin Endocrinol Metab. (2020) 34:101448. doi: 10.1016/j.beem.2020.101448

7. Michalkiewicz E, Sandrini R, Figueiredo B, Miranda ECM, Caran E, Oliveira-Filho AG, et al. Clinical and outcome characteristics of children with adrenocortical tumors: a report from the international pediatric adrenocortical tumor registry. JCO. (2004) 22:838-45. doi: 10.1200/JCO.2004.08.085

8. Ribeiro RC, Figueiredo B. Childhood adrenocortical tumours. Eur J Cancer. (2004) 40:1117-26. doi: 10.1016/j.ejca.2004.01.031

9. Cecchetto G, Ganarin A, Bien E, Vorwerk P, Bisogno G, Godzinski J, et al. Outcome and prognostic factors in high-risk childhood adrenocortical carcinomas: A report from the European Cooperative Study Group on Pediatric Rare Tumors (EXPeRT): Cecchetto et al. Pediatr Blood Cancer. (2017) 64:e26368. doi: 10.1002/pbc.26368

10. McAteer JP, Huaco JA, Gow KW. Predictors of survival in pediatric adrenocortical carcinoma: a Surveillance, Epidemiology, and End Results (SEER) program study. J Pediatr Surg. (2013) 48:1025-31. doi: 10.1016/j.jpedsurg.2013.02.017

11. Wieneke JA, Thompson LDR, Heffess CS. Adrenal cortical neoplasms in the pediatric population: a clinicopathologic and immunophenotypic analysis of 83 patients. Am J Surg Pathol. (2003) 27:867-81. doi: 10.1097/00000478-200307000-00001

12. Fassnacht M, Terzolo M, Allolio B, Baudin E, Haak H, Berruti A, et al. Combination chemotherapy in advanced adrenocortical carcinoma. $N$ Engl J Med. (2012) 366:2189-97. doi: 10.1056/NEJMoa1200966

13. Berruti A, Baudin E, Gelderblom H, Haak HR, Porpiglia F, Fassnacht M, et al. Adrenal cancer: ESMO Clinical Practice Guidelines for diagnosis, treatment and follow-up. Ann Oncol. (2012) 23:vii131-8. doi: 10.1093/annonc/mds231

14. Pinto EM, Chen X, Easton J, Finkelstein D, Liu Z, Pounds S, et al. Genomic landscape of paediatric adrenocortical tumours. Nat Commun. (2015) 6:6302. doi: 10.1038/ncomms7302

15. Teinturier C, Pauchard MS, Brugières L, Landais P, Chaussain JL, Bougnères PF. Clinical and prognostic aspects of adrenocortical neoplasms in childhood. Med Pediatr Oncol. (1999) 32:106-11. doi: 10.1002/(SICI)1096911X(199902)32:2<106::AID-MPO7>3.0.CO;2-J

16. Kerkhofs TMA, Ettaieb MHT, Verhoeven RHA, Kaspers GJL, Tissing WJE, Loeffen J, et al. Adrenocortical carcinoma in children: first populationbased clinicopathological study with long-term follow-up. Oncol Rep. (2014) 32:2836-44. doi: 10.3892/or.2014.3506

\section{ACKNOWLEDGMENTS}

We thank William Marc Silberg from the Department of Surgery, IRCCS Bambino Gesù Children's Hospital for providing writing support.

17. Fassnacht M, Dekkers OM, Else T, Baudin E, Berruti A, de Krijger RR, et al. European Society of Endocrinology Clinical Practice Guidelines on the management of adrenocortical carcinoma in adults, in collaboration with the European Network for the Study of Adrenal Tumors. Eur J Endocrinol. (2018) 179:G1-46. doi: 10.1530/EJE-18-0608

18. Wang Z, Liu G, Sun H, Li K, Dong K, Ma Y, et al. Clinical characteristics and prognosis of adrenocortical tumors in children. Pediatr Surg Int. (2019) 35:365-71. doi: 10.1007/s00383-018-4409-Z

19. Kato S, Han S-Y, Liu W, Otsuka K, Shibata H, Kanamaru R, et al. Understanding the function-structure and function-mutation relationships of p53 tumor suppressor protein by high-resolution missense mutation analysis. Proc Natl Acad Sci U S A. (2003) 100:8424-9. doi: 10.1073/pnas.1431692100

20. Giacomelli AO, Yang X, Lintner RE, McFarland JM, Duby M, Kim J, et al. Mutational processes shape the landscape of TP53 mutations in human cancer. Nat Genet. (2018) 50:1381-7. doi: 10.1038/s41588-018-0204-y

21. Toguchida J, Yamaguchi T, Dayton SH, Beaughamp RL, Herrera GE, Ishizaki K, et al. Prevalence and spectrum of germline mutations of the p53 gene among patients with sarcoma. N Engl J Med. (1992) 326:13018. doi: 10.1056/NEJM199205143262001

22. Smardova J, Liskova K, Ravcukova B, Malcikova J, Hausnerova J, Svitakova M, et al. Complex analysis of the p53 tumor suppressor in lung carcinoma. Oncol Rep. (2016) 35:1859-67. doi: 10.3892/or.2015.4533

23. Wasserman JD, Novokmet A, Eichler-Jonsson C, Ribeiro RC, RodriguezGalindo C, Zambetti GP, et al. Prevalence and functional consequence of TP53 mutations in pediatric adrenocortical carcinoma: a Children's Oncology Group Study. JCO. (2015) 33:602-9. doi: 10.1200/JCO.2013. 52.6863

24. Ruijs MWG, Verhoef S, Rookus MA, Pruntel R, van der Hout AH, Hogervorst FBL, et al. TP53 germline mutation testing in 180 families suspected of Li-Fraumeni syndrome: mutation detection rate and relative frequency of cancers in different familial phenotypes. J Med Genet. (2010) 47:4218. doi: 10.1136/jmg.2009.073429

25. Epstein CB, Attiyeh EF, Hobson DA, Silver AL, Broach JR, Levine AJ. p53 mutations isolated in yeast based on loss of transcription factor activity: similarities and differences from p53 mutations detected in human tumors. Oncogene. (1998) 16:2115-22. doi: 10.1038/sj.onc.1201734

26. Cho JY, Lee YH. Fetal tumors: prenatal ultrasonographic findings and clinical characteristics. Ultrasonography. (2014) 33:240-51. doi: 10.14366/usg.14019

27. Jedrzejewski G, Wozniak MM, Pawelec A, Matera A, Kunach M, Madej T, et al. Ultrasound screening for neoplasms in children up to 6 years old. Medicine. (2016) 95:e5124. doi: 10.1097/MD.0000000000005124

28. Hanafy AK, Mujtaba B, Roman-Colon AM, Elsayes KM, Harrison D, Ramani NS, et al. Imaging features of adrenal gland masses in the pediatric population. Abdom Radiol. (2020) 45:964-81. doi: 10.1007/s00261-019-02213-x

29. McNeil DE, Brown M, Ching A, DeBaun MR. Screening for Wilms tumor and hepatoblastoma in children with Beckwith-Wiedemann syndromes: a cost-effective model. Med Pediatr Oncol. (2001) 37:349-56. doi: 10.1002/mpo. 1209

30. Picard C, Orbach D, Dijoud F. Reply to "Pathological prognostication of pediatric adrenocortical tumors: is a gold standard emerging?” Pediatr Blood Cancer. (2019) 66:e27710. doi: 10.1002/pbc.27710

31. Picard C, Orbach D, Carton M, Brugieres L, Renaudin K, Aubert S, et al. Revisiting the role of the pathological grading in pediatric adrenal cortical tumors: results from a national cohort study with pathological review. Mod Pathol. (2019) 32:546-59. doi: 10.1038/s41379-018-0174-8

32. Porpiglia F, Fiori C, Daffara F, Zaggia B, Bollito E, Volante M, et al. Retrospective evaluation of the outcome of open versus laparoscopic adrenalectomy for stage I and II adrenocortical cancer. Eur Urol. (2010) 57:873-8. doi: 10.1016/j.eururo.2010.01.036 
33. Varghese J, Habra MA. Update on adrenocortical carcinoma management and future directions. Curr Opin Endocrinol Diabetes Obesity. (2017). 24:20814. doi: 10.1097/MED.0000000000000332

34. Reidy-Lagunes DL, Lung B, Untch BR, Raj N, Hrabovsky A, Kelly $\mathrm{C}$, et al. Complete responses to mitotane in metastatic adrenocortical carcinoma-a new look at an old drug. Oncologist. (2017) 22:11026. doi: 10.1634/theoncologist.2016-0459

35. Daffara F, De Francia S, Reimondo G, Zaggia B, Aroasio E, Porpiglia F, et al. Prospective evaluation of mitotane toxicity in adrenocortical cancer patients treated adjuvantly. Endocr Relat Cancer. (2008) 15:104353. doi: 10.1677/ERC-08-0103

36. Polat B, Fassnacht M, Pfreundner L, Guckenberger M, Bratengeier K, Johanssen S, et al. Radiotherapy in adrenocortical carcinoma. Cancer. (2009) 115:2816-23. doi: 10.1002/cncr.24331

37. Jouinot A, Bertherat J. MANAGEMENT OF ENDOCRINE DISEASE: adrenocortical carcinoma: differentiating the good from the poor prognosis tumors. Eur J Endocrinol. (2018) 178:R215-30. doi: 10.1530/EJE-18-0027

38. Redlich A, Boxberger N, Strugala D, Frühwald M, Leuschner I, Kropf S, et al. Systemic treatment of adrenocortical carcinoma in children: data from the German GPOH-MET 97 Trial. Klin Padiatr. (2012) 224:36671. doi: 10.1055/s-0032-1327579

39. Berruti A, Terzolo M, Pia A, Angeli A, Dogliotti L. Mitotane associated with etoposide, doxorubicin, and cisplatin in the treatment of advanced adrenocortical carcinoma. Italian Group for the Study of Adrenal Cancer. Cancer. (1998) 83:2194-200. doi: 10.1002/(SICI)10970142(19981115)83:10<2194::AID-CNCR19>3.0.CO;2-3

40. Zancanella P, Pianovski MAD, Oliveira BH, Ferman S, Piovezan GC, Lichtvan LL, et al. Mitotane associated with cisplatin, etoposide, and doxorubicin in advanced childhood adrenocortical carcinoma: mitotane monitoring and tumor regression. J Pediatr Hematol Oncol. (2006) 28:51324. doi: 10.1097/01.mph.0000212965.52759.1c

41. Guntiboina VA, Sengupta M, Islam N, Barman S, Biswas SK, Chatterjee $\mathrm{U}$, et al. Diagnostic and prognostic utility of SF1, IGF2 and p57 immunoexpression in pediatric adrenal cortical tumors. J Pediatr Surg. (2019) 54:1906-12. doi: 10.1016/j.jpedsurg.2018.12.002

42. Fassnacht M, Berruti A, Baudin E, Demeure MJ, Gilbert J, Haak H, et al. Linsitinib (OSI-906) versus placebo for patients with locally advanced or metastatic adrenocortical carcinoma: a double-blind, randomised, phase 3 study. Lancet Oncol. (2015) 16:426-35. doi: 10.1016/S1470-2045(15)70081-1
43. Raj N, Zheng Y, Kelly V, Katz SS, Chou J, Do RKG, et al. PD1 blockade in advanced adrenocortical carcinoma. JCO. (2020) 38:7180. doi: 10.1200/JCO.19.01586

44. Naing A, Meric-Bernstam F, Stephen B, Karp DD, Hajjar J, Rodon Ahnert $\mathrm{J}$, et al. Phase 2 study of pembrolizumab in patients with advanced rare cancers. J Immunother Cancer. (2020) 8:e000347. doi: 10.1136/jitc-2019000347

45. Habra MA, Stephen B, Campbell M, Hess K, Tapia C, Xu M, et al. Phase II clinical trial of pembrolizumab efficacy and safety in advanced adrenocortical carcinoma. J Immunother Cancer. (2019) 7:253. doi: 10.1186/s40425-019-0722-x

46. Geoerger B, Kang HJ, Yalon-Oren M, Marshall LV, Vezina C, Pappo A, et al. Pembrolizumab in paediatric patients with advanced melanoma or a PD-L1-positive, advanced, relapsed, or refractory solid tumour or lymphoma (KEYNOTE-051): interim analysis of an open-label, single-arm, phase 1-2 trial. Lancet Oncol. (2020) 21:121-33. doi: 10.1016/S1470-2045(19) 30671-0

47. Song $\mathrm{H}$, Hollstein $\mathrm{M}, \mathrm{Xu} \mathrm{Y}$. p53 gain-of-function cancer mutants induce genetic instability by inactivating ATM. Nat Cell Biol. (2007) 9:57380. doi: $10.1038 /$ ncb1571

48. Pinto EM, Rodriguez-Galindo C, Pounds SB, Wang L, Clay MR, Neale $\mathrm{G}$, et al. Identification of clinical and biologic correlates associated with outcome in children with adrenocortical tumors without germline TP53 mutations: a St Jude Adrenocortical Tumor Registry and Children's Oncology Group Study. JCO. (2017) 35:3956-63. doi: 10.1200/JCO.2017.74. 2460

Conflict of Interest: The authors declare that the research was conducted in the absence of any commercial or financial relationships that could be construed as a potential conflict of interest.

Copyright (c) 2020 Miele, Di Giannatale, Crocoli, Cozza, Serra, Castellano, Cacchione, Cefalo, Alaggio and De Pasquale. This is an open-access article distributed under the terms of the Creative Commons Attribution License (CC BY). The use, distribution or reproduction in other forums is permitted, provided the original author(s) and the copyright owner(s) are credited and that the original publication in this journal is cited, in accordance with accepted academic practice. No use, distribution or reproduction is permitted which does not comply with these terms. 